\title{
Wikipedia and the Myth of Universality
}

\author{
Melissa Adler
}

\section{Bio}

Melissa Adler, Ph.D., is Assistant Professor in the School of Information Science and Faculty Affiliate with Gender \& Women's Studies and the Committee on Social Theory at the University of Kentucky. Her work situates classification and naming at the heart of the intersections across information studies, sexuality studies, critical race and ethnic studies, American studies, and critical theory. Her forthcoming book, The Perverse Library: Knowledge Organization and the History of Sexuality, examines Library of Congress classifications for sexuality and will be published by Fordham University Press. She is also creating a digital catalog of the Library of Congress's post-World War II Delta Collection, a restricted collection of materials deemed to be obscene: http://deltacollection.omeka.net/. Melissa has published in Information \& Culture, the Journal of the History of Sexuality, and Knowledge Organization. She is the 2015 chair of the Classification Research group of the Association for Information Science and Technology and serves on the editorial board of the Journal of Critical Library and Information Studies.

Melissa Adler, Assistant Professor

School of Information Science,

University of Kentucky, USA

melissa.adler@uky.edu

\section{Introduction}

I write from the U.S., where the removal of "women writers" from the more general and inclusive "writers" category in 2013 drew national ire and debate (Filipacchi, 2013). The episode heightened visibility of the fact that Wikipedia entries are not only predominantly created and edited by men, but that the categories that organize the content are also gendered and hierarchical. Indeed, classification is arguably at the root of some of the most critical questions regarding Wikipedia's functions and limitations. The construction of categories for access to knowledge and information is inherently paradoxical-it is by way of categories that we organize and access information in any information retrieval system. But categories are by definition limiting and exclusionary, and they operate on the basis of membership and nonmembership: an inside and an outside. Membership and the terms by which we name those categories-especially with regard to humans and human subjectivities-are almost always political and contested.

Wikipedia's classification problem is directly tied to its aspirations toward universality. To demonstrate what I mean, I begin with the oft-cited proclamation of Wikipedia's mission as explained by co-founder Jimmy Wales in 2004: "Imagine a world in which every single person on the planet is given free access to the sum of all human knowledge. That's what we're doing" (quoted Miller, 2004). This statement strikes one as particularly problematic when read in 
tandem with one of Wikipedia's five "pillars," which states that all entries are "written from a neutral point of view" (Wikipedia, 2015). Claims about neutrality and universal access to a totalizing space for the benefit to all of humanity are premised upon the participatory nature of Wikipedia. The fantasy that anyone with access to the Internet can create and edit entries gives the sense that the possibility of compiling the "sum of all human knowledge" in one platform might actually be realizable; the presentation of multiple points of view, combined with consensus derived from deliberation and collective editing seems to ensure completeness and accuracy. What is more, the dream of becoming accessible to all corners of the world suggests that it is universal not just in scope and perspective, but also in reach, and the notion that it will continue to accommodate an ever-growing amount of knowledge means that it is unbound by time and potentially infinite.

Jimmy Wales is certainly not the first person to assert that an all-encompassing knowledge system could radically change the world for the good. Faith in the securitizing and educational promise of collecting, collating, and classifying all the world's knowledge dates back at least as far as the Enlightenment. Such beliefs were a driving force for Diderot and D'Alembert's 18th century Encyclopedie, which was created to facilitate communication and learning to advance the human race. Similarly, from 1904 to 1907 Paul Otlet and Nobel Peace Prize recipient Henri LaFontaine published the Universal Decimal Classification (which is still used in much of Europe and in other areas of the world) to organize a massive collection of materials. They had a vision for a networked global information sharing system known as the Mundaneum, which scholars now view to be a precursor to hypertext and the Internet (Day, 1997; Van den Heuvel \& Rayward, 2011). And, in fact, the essential property of the World Wide Web is its universality, according to creator Tim Berners-Lee (2010, p. 82).

Indeed, there is a long tradition of creating large knowledge organization systems to improve the world. Crafters of "universal" knowledge organization systems have consistently aimed to facilitate access to vast information resources across cultural and political borders in order to bring shared understanding, and even world peace. While there is certainly tremendous good that has come out of these vastly powerful systems, one cannot overlook certain negative consequences. Where there are claims to universality and systems built upon the belief in the truth that such a thing is possible, we must interrogate the ethical and moral dimensions associated with the universalisms upon which those systems are constructed. In sharp contrast to the idea that universal classifications can facilitate peaceful relations, Max Horkheimer and Theordor Adorno (1997) identify classification as a primary technique of the Enlightenment's rationalization of dominance (p. 12). According to them, thinking has been abandoned to categories, mathematics, rationalism, and universalisms. One of the mechanisms of universalism is the excision of incommensurability, or the erasure of subjects that don't conform to the dominant system. I would argue that aspirations to universality actually undermine knowledge organization systems and fail to recognize excluded and marginalized subjects upon which claims to universality rely. And it is worth asking whether and for whom aspirations toward universality in reach and scope are desirable and good. The need for feminist critique is all the more pressing, as blindnesses and exclusions are often built into these "universal" systems. In American- and European-designed systems patriarchy, heterosexuality, whiteness are universalized, as are Western ideals about knowledge, research, education, and truth. For example, the requirement for inclusion in Wikipedia of verifiability sets up serious limitations and rules for what counts as authoritative. Interpretation, speculation, and knowledges passed along by traditions are generally prohibited. These forms of knowledge are allowed if described by an expert who can write "objectively" about certain perspectives, but not from them.

The central concern here has to do with the universal and the particular, the global and the local, the masses and community. In Problems of Moral Philosophy Theodor Adorno argues that this is the key problem of morality. Although he is careful to eschew the suggestion that universalisms are always to blame and the individual is always good, Adorno does explain that universalisms become violent when they fail to account for and accommodate the particular "the accidental, the contingent, the psychological." They become abstractions that have "no substantial reality for human beings" (Adorno, 2001, p. 19). This is why local participatory systems are essential. It is not simply a matter of augmenting larger 
systems, but of recognizing the value of creating and organizing knowledge from various points of view.

Local and particular systems can serve as sources of resistance to the majoritarian impulse of Wikipedia.

One might be tempted to view Wikipedia as a model of "strong objectivity," as described by Sandra Harding and Karen Barad. It houses, organizes, and distributes information from multiple positions on potentially infinite topics (Harding, 1992; Barad, 2007). People in all kinds of situations and locations contribute to the encyclopedia, and in a sense, the process of revising and editing is much like a conversation that aims to arrive at the most informative entries. However, Wales has said that his inspiration for Wikipedia derived from reading Frederich Hayek's "The Use of Knowledge in Society" - a foundational neoliberal text that argues for a market-based approach to knowledge. (van Bree, 2010; Hayek, 1945). This is a particularly interesting detail because the Hayek piece emphasizes the notion that no single person can know everything, and it calls for a decentralized pooling of local knowledge from many individuals. But the libertarian emphasis on free market principles and individualism means that the resulting knowledge is nothing like what Harding and Barad imagine. The conditions of verifiability and consensus required by Wikipedia mean the ideal of strong objectivity can never be attained in this space. Libertarianism celebrates competition, rather than coexistence, and when there is disagreement or variation in perceptions, the page that appears as the topic's entry serves as the single position. It gains the status of authority - even if just for the moment, with the illusion that its objectivity is made even stronger by the power of consensus. The relative anonymity of its author means that we cannot have access to an understanding of the perspective from which the entry has been written and edited. Although there are pages that display the conversations around entries, these are not immediately visible. Thus a sense of the multiplicity of perspectives that may exist on any given topic is not readily apparent.

The reliance on authoritative sources and the exclusion of experience elevates published scholarship and data-centric methods, while masking the limitations of such knowledge formations. Consensus is actually code for the force and simplicity of the mainstream and the dominant. Information that is verified by "legitimate" sources will rule out the knowledges that are deemed not qualified to speak. Wikipedia commands a mastery of knowledge. It may be wise to heed the warning of the Tower of Babel, as it stands as an example of what happens when all of knowledge is united in a single edifice.

What is wonderful about Wikipedia is that debate results in real change - publicly, in fact, as it provides access to talk pages and page histories. For the most part, however, these kinds of conversations are unnoticed and hidden beneath the entries that appear to have achieved consensus. The erased minority points of view are hidden in layers of a palimpsest. This is true of the content of the entries, but also of the categories used to designate what those entries are about. The talk pages may be a fruitful place to reorganize and improve Wikipedia: bringing talk pages into full view and even featuring them as primary pages for a short time would increase visibility of the process, as well as the varying points of view. ${ }^{1}$ The case of the discovery of the removal of women writers from the general category of writers illustrates the potential efficacy of highlighting editors' conversations and revisions. When Amanda Filipacchi brought the problem to public attention, a public outcry from media outlets, including the New York Times and The Atlantic, prompted action and discussion. The controversy led to women writers being put back into the general "writers" category - now they are "women writers" and "writers." Categories for "male writers" were also introduced. This case makes our collective and particular investments in gender difference hypervisible. It gives a certain presence to the sometimes hidden insistence on gender categories in society. The assumptions underlying the decision to categorically remove women from the general are propelled by widely held beliefs about gender difference. In "universal" systems like Wikipedia, which reflect mainstream attitudes and beliefs, maleness stands as the default universalized norm against which other categories are marked.

One might reasonably ask whether it is ever possible for a participatory archive or knowledge organization system to overcome the paradox that stems from the necessity of control and discipline for the purpose of access and retrieval. Perhaps the better question is one that challenges us to dig into and confront that paradox, which is inherent in any system built upon categories. Hierarchies and relationships are organized on the basis of associations, which assume and 
mirror a social existence. Critique facilitates an understanding of the relations of power and helps us come to grips with what is at stake in participatory knowledge organization systems. Consciousness of the ethical questions around control for access in advance might lead to more just categories that respond to conflict and change.

Wikipedia is constructed out of a myth of universality. In practice, universal classifications fail to accommodate certain subjects outside of universalized norms; universalized knowledge fails to recognize unverifiable knowledge; and universal access fails to recognize the social and political barriers to realizing such an ideal (as well as the potential harmful consequences of certain initiatives toward universal access). Honoring the particular within a system that aspires toward universality and built on categories is simply not possible.

Still, there is tremendous value and need for antiracist, decolonialist, feminist, and queer perspectives in Wikipedia. There are topics that remain underrepresented and content that demands to be written, even within the parameters of verifiability. There is certainly room for improvement in the creation and application of categories. But perhaps more significant is the call to encourage and support the creation of particular systems that contain partial knowledges-local and community archives that organize and name their resources according to their own standards and vocabularies. Site, time, and community-specific systems do not claim to be uniting the entire world under one system. Rather, they provide critical content from points of view that those all-encompassing systems often fail to support. Certain local systems are likely to arrive at more just ways of bringing otherwise disqualified knowledges to the surface, categorizing and naming their content, and opening up spaces for dialogue and critique (Foucault, 1977, p. 82). ${ }^{2}$ Difference of opinions and points of view can be expressed across sites with varying and sometimes competing interests in related topics, in contrast to the compulsory consensus of Wikipedia. In combination, a multitude of participatory archives from particular and minority perspectives offer the possibility of much richer and complex and varied truths of the world. ${ }^{3}$

\section{Notes}

1. Thanks to Nanna Bonde Thylstrup for this suggestion.

2. "It is through the re-appearance of this knowledge, of these local popular knowledges, the disqualified knowledges, that criticism performs its work."

3. There are too many examples to cite. Among those in North America are the Chicano Por Mi Raza Digital Memory Collective: http://chicanapormiraza.org/; the Queer Zine Archive Project (QZAP): http://www.qzap.org/v8/index.php; and the LGBTQ Digital Collaboratory, which links out to dozens of independent projects: http://gbtqdigitalcollaboratory.org/oral-history-hub/. I am also building a digital catalog of the Library of Congress's former Delta Collection, which hid "obscene" materials from view and excluded it from it's general collection. It is an attempt to reclaim history and speak back to the classificatory techniques used to mark materials as exceptions to universalized norms. http://deltacollection.omeka. net/

\section{References}

Adorno, TW (2011). Problems of moral philosophy. T. Schröder (Ed.). (R. Livingstone, Trans). Stanford, CA: Stanford University Press.

Barad, K (2007). Meeting the universe halfway: Quantum physics and the entanglementof matter and meaning. Durham, NC: Duke University Press.

Berners-Lee, T (2010). Long live the Web. Scientific American, 303 (6): 80-85.

Day, R (1997). Paul Otlet's book and the writing of social space. Journal of the American Society for Information Science, 48 (4): 310-317.

Filipacchi, A (2013, April 24). Wikipedia's sexism toward female novelists. New York Times. Retrieved from http://www.nytimes.com/2013/04/28/opinion/ sunday/wikipedias-sexism-toward-female-novelists. html 
Foucault, M (1978). Two Lectures, in Power/Knowledge: Selected Interviews and Other Writings, 19721977, Colin Gordon (Ed.). New York: Pantheon.

Harding, S (1992). Rethinking standpoint epistemology: What is "strong objectivity? Centennial Review 36 (3): 437-470.

Hayek, FA (1945). The use of knowledge in society. The American Economic Review, 35: 519-530.

Horkheimer, M \& Adorno, TW (1997). Dialectic of enlightenment. New York: Verso.

Miller, R (2004, July 28). Wikimedia founder Jimmy Wales responds. Slashdot. Retrieved from http:// slashdot.org/story/04/07/28/1351230/wikipediafounder-jimmy-wales-responds

van Bree, P (2010, October 5). Californian ideology 2.0, a first farewell. Masters of Media. Retrieved from http://mastersofmedia.hum.uva.nl/2010/10/05/ californian-ideology-2-0-a-first-farewell/

Van den Heuvel, C \& Rayward, WB (2011). Facing interfaces: Paul Otlet's visualizations of data integration. Journal of the American Society for Information Science and Technology, 62 (12): 2313-2326.

Wikipedia (2015). Wikipedia: Five pillars, Retrieved from https://en.wikipedia.org/wiki/Wikipedia:Five pillars. 